\section{WHIPSNADE ZOOLOGICAL PARK}

\author{
By DR. L. HARRISON MATTHEWS \\ Zoological Society of London
}

T HIS year Whipsnade Zoological Park celebrates its coming of age. In less than a generation the Zoological Society of London has transformed a derelict Bedfordshire estate into one of the most famous zoological parks in the world, and the name of Whipsnade has become a household word. In addition to Whipsnade's achievements in the field of zoological science, it has become recognized as a national institution where more than half a million visitors find interest, relaxation and entertainment every year.

The Park occupies an area of more than five hundred acres on the northern slopes of the Dunstable Downs, marked by the gigantic figure of a lion cut through the turf into the white chalk. Tne landscape is well varied, consisting of woodland, meadow and downland, and provides an ideal setting for the display of animals in natural surroundings. The estate is served by several miles of metalled roads and innumerable tracks and paths; recently a road train has been installed to carry visitors to the main points of interest.

The range of animals now shown at Whipsnade is larger than ever before. Lions and tigers inhabit natural pits on the northern slopes of the downs; alongside them are the polar bears in an enclosure resembling as nearly as possible their Arctic home. In the woods near Whipsnade Gate are found pumas, cheetahs, dingos and a troop of rhesus monkeys. In Wolf Wood a Spruce plantation provides a fitting background for the wolves, which are perhaps seen to best advantage after a fall of snow. A fine herd of bison occupies one of the large paddocks on the northern slopes and does well in the open in all weathers. More surprising, perhaps, are the hippopotamus, which are acclimatized to live in the open all the year round, making use of only an open shelter with some artificial heat in the most severe weather. One of the most spectacular exhibits of the Park is the Kodiak bears, the largest race of the grizzly. The male Indian rhinoceros is remarkably docile, and may perhaps breed with the young female which the Society has recently acquired and hopes shortly to import from Assam. Some of the most charming features of the Park are the large numbers of wallabies and some of the smaller species of deer that run wild over the estate.

Although less spectacular than the mammals, the birds at Whipsnade also make a fascinating display. Nearly every paddock has its quota of rheas, ostriches, cranes or exotic geese. Peafowl wander at liberty and display themselves proudly on the lawns, while the flamingo pond by the main restaurant is one of the most beautiful sights in the Park. 'The British wild birds have their own natural sanctuary, and many species breed there every year.

Whipsnade owes its origin to the vision and energy of the late Sir Peter Chalmers Mitchell, for many years secretary of the Soviety. He thought of it first as a home for reserve stock and also as a kind of 'holiday camp' for the animals in the Society's collection at Regent's Park, London. The fact that Whipsnade has now become much more than this and is now a zoological park in its own right only endorses the excellence of his views.

When first purchased, the estate consisted of semiderelict farmland and was unfenced. The first move in establishing the Park was to surround the whole area with a wire fence $9 \mathrm{ft}$. high and $4 \frac{1}{2}$ miles long. This fence was originally fitted with an overhanging section facing inwards to prevent the escape of animals ; but it had later to be turned outwards, for it was found to be more important to keep foxes out than the animals in. Roads were made, paddocks laid out, and the old farm buildings were converted into a restaurant. The thickets and undergrowth were cleared, and the planting of natural panoramic backgrounds, which are now such a feature of the main paddocks, was begun. Shelters were put up and the paddocks fenced off and the nucleus of the collection was installed.

'The first day of Whipsnade's life was eventful and dramatic. 'The Society's most optimistic hopes were not only realized but exceeded-so much so, in fact, that the situation very nearly degenerated into chaos. The roads leading to the Park were inadequate to deal with the volume of traffic they were called upon to carry, for everyone had failed to foresee Whipsnade's immense popularity. As a result, every approach to the Park was blocked with motor-cars, and the Bedford Constabulary had to be turned out in force to deal with the situation. At the Park itself the turnstiles were overwhelmed by the avalanche of visitors, and the catering staff found themselves totally unable to cope with the surging crowds clamouring for refreshments. All these early troubles have long since been corrected; a new road has been constructed and old roads widened so that a visit to Whipsnade is easily and comfortably made.

'i'he early popularity of Whipsnade was more than maintained in the years before the Second World War, and in 1937 there was a record entry of some half a million visitors. Dr. Julian Huxley, who followed Sir Peter Chalmers Mitchell as the Society's secretary from 1935 until 1942, was particularly interested in Whipsnade, and it is to his initiative that the Park owes the Gibbon. Island and the picturesque Flamingo Pond by the Hall Farm Restaurant. At the outbreak of war in 1939, Whipsnade became an evacuation centre for many of the animals from the London $Z_{0 o}$, including the Indian riding elephants and the giant panda.

In the winter of 1939-40 the Park was closed, but it was re-opened the following spring and has never been closed since. Even in 1941, at the height of war-time misfortunes, the attendance figures reached nearly a quarter of a million. As part of the war-time drive for food, a hundred and sixty acres which had formerly been farmland were put back under cultivation, and to economize in animal feeding stuffs much valuable stock had to be destroyed. One unexpected problem which the Society had to solve during the War was the camouflaging of the white lion carved in the chalk of the Dunstable Downs ; it had to be hastily covered with earth and brushwood. As its outline measures more than three-quarters of a mile in length, this was by no means a simple task, and the lion's subsequent resurrection after the War took several weeks.

Although restrictions since the War have necessarily limited the building of new shelters and houses, a few simple modifications to the paddocks have greatly improved the visitor's view of the animals. Several of the boundary fences have been replaced 
by low barriers and dykes of the ha-ha type, so that visitors no longer have their vision impeded by wire netting. This device makes possible the illusion that one is actually walking in the same enclosure as the animals and has gone a long way to realize the ideal of a 'zoo without bars' which Whipsnade's originators hoped it would one day become.

Whipsnade has recently acquired several interesting additions, including leopards, penguins and sea lions; giraffes have been bred and reared for two years in succession. There are magnificent herds of eland, zebra, and many other species of the larger ruminants, and a small group of the interesting Ankole cattle which have recently been successfully bred. An enclosure has now been constructed around an old oak tree in which a colony of pandas has been established.

An important part of Whipsnade that is not seen by the ordinary visitor are the breeding pens for waterfowl and exotic pheasants, where a most interesting collection of birds is kept in a secluded fold of the hills and many species are successfully bred, much to the profit of the Society. Two years ago a stoat broke into these enclosures one night and did much damage.

New animals arrive at Whipsnade nearly every week, and as soon as conditions permit it is hoped that the Park's amenities may be still further improved. Projects that the Society is particularly anxious to carry out are the building of a new chimpanzee house, a still larger enclosure for the polar bears with a really deep pool, and an elephant lawn. At the moment, of course, these projects must remain only plans; but undoubtedly after the achievements of the past twenty-one years, Whipsnade can celebrate its coming of age with every confidence in the future.

The opportunities for scientific work, particularly on the behaviour of animals, are very great at Whipsnade. These opportunities have as yet scarcely been made use of ; but it is hoped that before long they will be fully exploited and the Society will be able to present results of considerable scientific interest and importance.

\section{NEWS}

Aeronautical Engineering at Cambridge :

Sir Melvill Jones, C.B.E., F.R.S.

Sir Melvill Jones retires shortly from the Francis Mond chair of aeronautical engineering in the University of Cambridge, which he has occupied since its creation in 1919. Throughout his tenure he has brought to the chair rare distinction by his personal contribution to aeronautical knowledge, and through his outstanding qualities as a teacher. The direction of Sir Melvill's researches has throughout been concerned with the understanding of the fundamental scientific factors affecting the mechanics and aerodynamics of the flying machine, and with the application of this knowledge to the improvement of the performance of the machine. By combining scientific inquiry with a strong appreciation of the application of his thoughts, he has made a personal contribution not only to science, but also to practical aviation, which has had a distinct effect on the development of the aeroplane.

Early in his career, Sir Melvill was led to the investigation of the mechanics of flight, and particularly of the difficulties of flight at low speed. He made major contributions to the elimination of dangerous conditions of flight. He then turned to a study of the causes of aerodynamic resistance, and in 1927 published a classic paper in which he provided the first criterion for the aerodynamic efficiency of aircraft; this paper provoked a series of rapid advances in design because it showed what was possible and how it could be achieved. A careful study followed of the nature of the airflow in the boundary layer very close to the surface of a body, and led to important advances in the design of wings. He has recently published his latest findings in this field, and has demonstrated the scientific principles which, if properly applied, can lead to a further large reduction in the frictional resistance of aircraft. Sir Melvill's versatility is typified by two other episodes. Shortly after the First World War, he demonstrated the principles upon which accurate aerial survey has been developed. In the Second World War he turned his attention to aerial gunnery, and impressive results followed in the efficacy of the

\section{nd VIEWS}

Royal Air Force's fighter and bomber armament. Throughout, his work has been exceptional in the simplicity of his equipment, and by reason of the use of aircraft in flight as his laboratory.

Mr. W. A. Mair

Mr. W. A. MaIR, who succeeds Sir Bennett Melvill Jones, was born in 1917 of Scottish parents, and was educated at Highgate School and Clare College, Cambridge. After a distinguished career at Cambridge, in which he was awarded three of the four prizes for mechanical sciences, he spent a short period with Rolls-Royce, Ltd. In 1940 he joined the R.A.F. as an engineer officer, and was sent to the Royal Aircraft Establishment, Farnborough, where he remained until 1946. His work there was mainly on experimental aerodynamics, both model and fullscale. Mr. Mair had considerable experience in the design and erection of low-speed and high-speed tunnels, and took a very large share in the work involved in bringing the high-speed tunnel at Farnborough into operation. Later he controlled much of the experimental work in this tunnel. When the results of the early experiments on models of existing and projected fighters were obtained, the necessity for co-ordination with experiments in full-scale flight became apparent, and he began to take a closer interest in flight experiments at high speeds. In fact, some of the earliest. work on the effect of compressibility on the characteristics of a Spitfire in a dive was carried out on a machine instrumented by $\mathrm{Mr}$. Mair. $\mathrm{He}$ continued, however, to take an active interest in the control of the high-speed tunnel experiments. By 1946 , Prof. S. Goldstein had persuaded the University of Manchester that a Fluid Motion Laboratory should be set up there, and $\mathrm{Mr}$. Mair was put in charge. As a result of unremitting work, this Laboratory is now well equipped for experimental work on supersonic flow and has also a low-speed low-turbulence tunnel in use. Mr. Mair's own work there has been mainly on shock-wave boundary-layer interaction and related problems, and on experimental apparatus for research on highspeed flow; but a variety of other work has been 